\title{
Residential greenness and adiposity: findings from the UK Biobank
}

\author{
Chinmoy Sarkar \\ aHealthy High Density Cities Lab, HKUrbanLab, The University of Hong Kong, Knowles \\ Building, Pokfulam Road, Hong Kong.
}

Published in:

Chinmoy Sarkar. 2017. Residential greenness and adiposity: Findings from the UK Biobank. Environment International, 106:1-10.

(pre-publication copy)

Available at: http://www.sciencedirect.com/science/article/pii/S0160412017302416

aCorrespondence to: Chinmoy Sarkar | csarkar@hku.hk | +852-3917 8193 |

Healthy High Density Cities Lab, HKUrbanLab, The University of Hong Kong, Knowles Building, Pokfulam Road. Hong Kong. 


\section{Abstract}

Background:

With the rapid urbanization and prevailing obesity pandemic, the role of residential green exposures in obesity prevention has gained renewed focus. The study investigated the effects of residential green exposures on adiposity using a large and diverse population sample drawn from the UK Biobank.

Materials and methods:

This was a population based cross-sectional study of 333183 participants aged 38-73 years with individual-level data on residential greenness and built environment exposures. Residential greenness was assessed through 0.50-metre resolution normalized difference vegetation index (NDVI) derived from spectral reflectance measurements in remotely sensed colour infrared data and measured around geocoded participants' dwelling. A series of continuous and binary outcome models examined the associations between residential greenness and markers of adiposity, expressed as body-mass index (BMI) in $\mathrm{Kg} / \mathrm{m}^{2}$, waist circumference (WC) in $\mathrm{cm}$, whole body fat (WBF) in $\mathrm{Kg}$ and obesity $\left(\mathrm{BMI} \geq 30 \mathrm{Kg} / \mathrm{m}^{2}\right)$ after adjusting for other activity-influencing built environment and confounders. Sensitivity analyses involved studying effect modification by gender, age, urbanicity and SES as well as examining relationships between residential greenness and active travel behaviour.

Results:

Residential greenness was independently and consistently associated with lower adiposity, the association being robust to adjustments. An interquartile increment in NDVI greenness was associated with lower BMI $\left(\beta_{B M I}=-0.123 \mathrm{Kg} / \mathrm{m}^{2}, 95 \% \mathrm{Cl}:-0.14,-\right.$ $\left.0.10 \mathrm{Kg} / \mathrm{m}^{2}\right)$, WC ( $\left.\beta_{\mathrm{WC}}=-0.551 \mathrm{~cm}, 95 \% \mathrm{Cl}:-0.61,-0.50 \mathrm{~cm}\right)$, and $W B F\left(\beta_{W B F}=-0.138 \mathrm{Kg}\right.$, $95 \% \mathrm{Cl}:-0.18,-0.10 \mathrm{Kg})$ as well as a reduced relative risk of obesity $(\mathrm{RR}=0.968,95 \%$ $\mathrm{Cl}: 0.96,0.98)$. Residential greenness was beneficially related with active travel, being associated with higher odds of using active mode for non-work travel (OR=1.093, 95\% $\mathrm{Cl}: 1.08,1.11)$ as well as doing more than 30 minutes walking $(\mathrm{OR}=1.039,95 \% \mathrm{Cl}$ : $1.03,1.05)$.

Conclusion: 
32 Residing in greener areas was associated with healthy weight outcomes possibly

33 through a physical activity-related mechanism. Green allocation and design may act as

34 upstream-level public health interventions ameliorating the negative health externalities

35 of obesogenic urban environments. Further prospective studies are needed to identify

36 potential causal pathways and thereby effectively guide such interventions. '

37 Keywords: adiposity, body mass index, UK Biobank, NDVI, residential greenness,

38 UKBUMP, active travel.

39

40

41

42

43

44

45

46

47

48

49

50

51

52

53

54

55

56 


\section{Introduction}

Obesity is a global pandemic (Swinburn et al. 2011). Excessive adiposity is an important risk factor for morbidity and mortality from type 2 diabetes, cardiovascular disease and cancer (Flegal et al. 2007; Bhaskaran et al. 2014; Tobias et al. 2014). The role of built environment has long been established, especially in shaping daily lifestyles, walking, activity behaviours and adiposity outcomes (Brownson et al. 2009; Leal and Chaix 2011; Sallis et al. 2012; Sarkar et al. 2014). Residential green spaces, in particular, constitute a key health-promoting component of built environment (Depledge et al. 2011; Hartig et al. 2014). Exposures to residential green has been independently associated with higher levels of recreational and utilitarian walking and physical activity (Bedimo-Rung et al. 2005), lower odds of obesity (Lachowycz and Jones 2011), higher levels of social contacts and sense of community (Kweon et al. 1998). It has also been established to ameliorate adverse effects originating from exposures to air pollution (Nowak et al. 2006) and urban heat island effects (Loughner et al. 2012).

There is nonetheless some ambiguity in the relationships between residential greenness and physical activity and obesity and research evidence has been far from consistent. A recent systematic review (James et al. 2015) of twenty five cross sectional studies have reported intermediate-level evidence on the beneficial effects of residential greenness upon obesity. However, a few null (Potestio et al. 2009; Mowafi et al. 2012; Ord et al. 2013) and counterintuitive (Maas et al. 2008; Prince et al. 2011; Cummins and Fagg 2012) findings were also noted. Additionally, it is often difficult to establish the exact functional causality as most studies have focused on the protective effects of residential greenness outcomes accrued from their functional role as recreational spaces, often measured in terms of size, density and accessibility to residential park space. There has thus far been very few studies on the links between the functional role of residential green as salutogenic environmental spaces and adiposity (Sarkar et al. $2015 b)$. Furthermore, many of the studies measure residential green space at an aggregate level of analysis such as census-defined units or through satellite-derived metrics of lower spatial resolution, while most have been small scale studies within homogeneous environmental settings, thereby limiting accuracy, statistical reliability and generalizability. 
The present study examines the links between adiposity and residential greenness in a diverse UK-wide adult population employing data from the UK Biobank cohort and high resolution metrics of salutogenic green exposures after adjusting for other pertinent activity-influencing built environment, socio-demographics, lifestyle and co-morbidities. Effect modification by gender, age, urbanicity and SES was also tested.

\section{Materials and methods}

\subsection{Study sample}

The UK Biobank is a prospective population-based cohort of 502649 adults aged 37-73 years (99.5\% aged between $40-69$ years) established to study the lifestyle, environment and genetic determinants of a various adult diseases. The participants recruited at baseline (2006-2010) attended one of the 22 collection centres across UK for detailed assessment providing a range of information through extensive questionnaires on sociodemographics, lifestyle and medical history; anthropometric measurements; biological samples (blood, urine and saliva); imaging and hospital-related outcomes. Details of the study can be found elsewhere (Allen et al. 2014; Sudlow et al. 2015). The recruited participants resided within 25 miles of the collection centres and included participants residing in urban areas as well as some beyond the urban fringes (Figure 1). Built environment exposures within multi-scale residential neighbourhoods were modelled for the cohort participants. The cross sectional study employed N=353 670 (70.4\%) participants of the UK Biobank with valid data on residential green exposures. After exclusions on account of incomplete data on adiposity and individual-level confounders for 18438 (3.7\%), and built environment and air pollution exposure variables for 2049 $(0.4 \%)$ participants, an analytic sample of $\mathrm{N}=333183$ was available for analyses.

\section{[Insert Figure 1]}

\subsection{Adiposity measures}

Body mass index (BMI), waist circumference (WC), whole body fat (WBF) and obesity constituted the primary measures of adiposity. Standing height $(\mathrm{cm})$ was measured using a Seca 202 device and waist circumference $(\mathrm{cm})$ was enumerated using a Wessex non-stretchable sprung tape. Weight and whole body fat mass was measured using electrical bio-impedance with the Tanita BC-418 MA body composition analyser. 
Body Mass Index (BMI) was derived by dividing weight (kilograms) by square of standing height (square metres). Obesity was expressed as per as the World Health Organization's definition (cut-offs for $\mathrm{BMl} \geq 30 \mathrm{Kg} / \mathrm{m}^{2}$ ). Anthropometrics were assessed by trained technicians at the collection centres as the participants wore light clothes and no shoes.

2.3 Active travel behaviour Using active travel mode and doing more than 30 minutes walking were employed as secondary outcome variables of active travel behaviour. The UK Biobank participants were asked "In the last 4 weeks, which forms of transport have you used most often to get about? (Not including any journeys to and from work)" with the option of selecting one or more of the following: car/motor vehicle; walk; public transport; cycle. This was subsequently dichotomized into a binary variable; using active travel mode (walk, cycle, public transport) versus motorized transport (car/motor vehicle). The questionnaire on "average number of minutes spent walking on a typical day" was transformed in to a binary variable (doing more than 30 minutes walking versus doing less than 30 minutes).

\subsection{Environmental exposures}

Data on residential environment exposures were obtained from the UK Biobank Urban Morphometric Platform (UKBUMP). The UKBUMP is a linked database of objectively measured urban morphological metrics measuring health-influencing environmental exposures within functional neighbourhoods around UK Biobank participants' geocoded dwelling locations (Sarkar et al. 2015a; Sarkar and Webster 2017). Spatial and network analyses were performed upon diverse national-level spatial databases resulting in the automation of multiple health-specific neighbourhood metrics categorized as density, destination accessibility, street-level physical accessibility, food outlets accessibility, building class, greenness, terrain and neighbourhood deprivation. These exposure metrics have been subsequent linked back to the anonymized UK Biobank participant ids. Briefly, participant's dwelling addresses were first geocoded to the level of building footprints and dwelling neighbourhoods was defined within street network buffers 
centred on the geocoded locations in ArcGIS12 Network Analyst. Accurate data on building-level land uses and street networks were sourced from UK Ordnance Survey AddressBase Premium and MasterMap Integrated Transport Network databases. The UK-wide AddressBase Premium data of Ordnance Survey comprised approximately 36 million valid address point features with approximately 550 land use classifications. UKBUMP employed standard land-use classification scheme of the Ordnance Survey AddressBase Premium database and has land-use intensities of more than 200 health promoting/inhibiting land-use destinations within the defined dwelling neighbourhoods as well as measures of street distance to nearest, street network based measures of walkability. Residential greenness was modelled from a 0.50-metre color infrared imagery.

\section{Residential greenness}

Residential exposure to salutogenic green environment was measured with the help of Normalized Difference Vegetation Index (NDVI). The NDVI is an objective measure of overall salutogenic green exposure showing a strong correlation with expert's ratings in epidemiological research setting (Rhew et al. 2011) and has been employed in previous studies on links between green exposure and walkability (Sarkar et al. 2015b), physical activity (Almanza et al. 2012; Gong et al. 2014; McMorris et al. 2015) and adiposity (Bell et al. 2008; Pereira et al. 2013; Dadvand et al. 2014). It is a unit-less index of relative overall green vegetation or biomass derived from pixel values of spectral reflectance in remotely sensed data. The underlying principle employed in the NDVI calculation is that chlorophyll in healthy vegetation absorb radiation in the visible red region $(630-690 \mathrm{~nm})$ of the electromagnetic spectrum and reflect radiation in the near-infrared region (760$900 \mathrm{~nm}$ ). This differential absorbance and reflectance wavelengths by chlorophyll is employed as a proxy for green quality and intensity, as illustrated by the following formulae:

where RED and NIR stand for the spectral reflectance measurements acquired in the visible (red) and near-infrared regions of the electromagnetic spectrum. Index scores 
177 range between -1 to +1 with high negative values indicating water, those in the range 0 -

1780.1 representing barren rock, sand or snow, 0.2-0.3 corresponding to shrub and 179 grassland, while higher values indicating dense green vegetation.

180 A series of $0.50 \mathrm{~cm}$ by $0.50 \mathrm{~cm}$ resolution Colour Infrared (CIR) imagery collected by 181 Bluesky through specially developed sensors mounted underneath a survey aircraft was 182 employed in the present study. Summer-time images of the study areas collected over 183 similar temporal scales (across the baseline phase of UK Biobank study) were 184 employed to calculate mean NDVI values, thereby avoiding potential temporal mismatch and the resulting influence on account of seasonal variability in greenness. Large water bodies were excluded from the analyses. Residential greenness was measured as mean and standard deviation in the NDVI values within 500-metre catchment radius of geocoded UKB participants' dwellings. The criteria of 500-metre catchment for measuring residential green exposures in UKBUMP was informed by prior research 190 piloted in Caerphilly (Sarkar et al. 2014; Sarkar et al. 2013b) and Greater London (Sarkar et al. 2015). Previously, approximately a quarter mile (400-500 metres) distance 192 corresponding to 10-15 minutes travel time have been employed for measuring greenness (Villeneuve et al. 2012; Wolch et al. 2011; Gong et al. 2014). Neighbourhood urban environment

195 The study adjusted for potential activity-influencing residential environment through 196 variables derived from UKBUMP. Street-level neighbourhood walkability was modelled

197 in terms of betweenness centrality or through-movement potential of the street 198 segments. The method has been employed in active living research and described 199 elsewhere (Sarkar et al. 2013a; Sarkar et al. 2015b). The street network data of the 200 study areas comprising approximately 4 million street segments were extracted from the 201 OS MasterMap Integrated Transport Network database, transcribed in to an access 202 graph model and subjected to network analysis in sDNA (Chiaradia et al. 2012) to 203 model the street-level walkability within an 800 metres street catchment of UKB 204 participants' residence. It is expressed as the simulated counts of movement through 205 each link in the network, given its relative position and the topological connectivity with 
206 other segments within the network. sDNA betweenness of $\mathrm{x}$ in a graph of $\mathrm{N}$ links may

207 be defined as:

$208 \quad B t W l(x)=\sum_{y \varepsilon N} \sum_{z \varepsilon \boldsymbol{R}_{\boldsymbol{y}}} L(y) L(z) P(z) O D(y, z, x)$

209 where:

$210 y$ and $z$ are the geodesic end points;

$211 R_{y}$ is the set of links within a defined radius (800m in this case) from $y$;

$212 L(y)$ and $L(z)$ are length of links y and $z$ respectively;

$213 P_{z}$ is the proportion of link $z$ within the defined radius

214 OD is a function defined as:

$215 \quad O D=\left\{\begin{array}{r}1, \text { if } x \text { is on the geodesics from } y \text { to } z \\ \frac{1}{2}, \text { if } x \equiv y \equiv z z \\ \frac{1}{2}, \text { if } x \equiv z \equiv y \\ \frac{1}{2}, \text { if } x \equiv z \equiv y \\ 0, \text { otherwise }\end{array}\right.$

217 Density of retail outlets was sourced from expressed as the Ordnance Survey

218 AddressBase Premium database and expressed as the number $/ \mathrm{Km}^{2}$ of outlets within 1

$219 \mathrm{Km}$ residential street catchment. Other density measures employed in the study

220 included residential and public transport density within I Km street catchment.

221 Terrain was modelled from a 5-metre resolution Bluesky digital terrain model and 222 expresses as variability (standard deviation) of slope in degrees within a 0.5 kilometer 223 residential catchment.

224 Air pollution exposure

225 The study employed exposure to particulate matter as a proxy of traffic-related air 226 pollution. Residential exposures to particulate matter $\left(\mathrm{PM}_{2.5}\right.$ and $\left.\mathrm{PM}_{10}\right)$ was obtained 227 from UK Biobank's linked air pollution exposure data. PM was monitored three times for 22814 days, in the cold, warm and intermediate seasons of the year. Land use regression 
229 models were employed to estimate individual annual exposure to PM concentrations

230 around residential addresses (Eeftens et al. 2012).

231

232

233

234

235

236

237

238

239

240

241

242

243

244

245

246

247

248

249

250

251

252

253

254

255

256

257

258

Covariates

Socio-demographic covariates comprised age in years, gender, ethnicity, education, and employment status. SES was assessed through census-based Townsend deprivation scores which is a composite index of four variables (household overcrowding, unemployment, non-home ownership and non-car ownership) with low values representing high SES status and linked to the postcode of residence of UK Biobank participants. Smoking status was included as three-factor lifestyle level variable. The models also adjusted for prevalence of two pre-existing comorbidities; namely doctor diagnosed vascular disease and diabetes.

\subsection{Statistical analyses}

A series of linear regression models were employed to examine the associations between residential greenness and BMI, WC and WBF. Poisson regression with robust estimator assessed the relative risk $(R R)$ ratios for obesity in relation to residential greenness. Risk ratios provide a more accurate and unbiased estimation as compared to the odds ratios when the clinical outcome under investigation is common; i.e. a prevalence higher than 10\% (Cummings 2009).

Both continuous and categorical NDVI models were developed. In the continuous models, the association between residential green exposures and adiposity were expressed in terms of an interquartile increment in NDVI index. NDVI was also categorized in to quartiles and used as a four-factor variable. Initial data quality checks performed on all predictor variables included assessment of multicollinearity and model fit to ensure a parsimonious fit. First set of models (Model 1) adjusted for potential confounding by age (coded as 38-50, 51-60 and 61-73 years), gender (coded as female; male), ethnicity (coded as British; others), education (five-factor variable coded as none; O levels/GCSEs/CSEs; A levels/AS levels; NVQ/HND/HNC/Other professional; and College or University degree), and employment (three-factor variable coded as employed; retired; and unemployed, home maker, others), smoking status (coded as non-smoker, previous smoker and current smoker), vascular disease (none; 
259 high blood pressure; and heart attack/ angina/ stroke) and diabetes (yes versus no).

260 Second set of models (Model 2) adjusted additionally for SES. Townsend scores were 261 categorized in to quintiles and used as a 5-factor variable. Fully adjusted models (Model

262 3) further adjusted for built environment exposures (walkability, retail density and terrain 263 variability) as well as air pollution exposures $\left(\mathrm{PM}_{2.5}\right.$ and $\left.\mathrm{PM}_{10}\right)$. Walkability and retail 264 density were categorized in to quartiles and employed as 4-factor variables.

265 As further sensitivity analyses, effect modification by gender, age, urbanicity and SES 266 after adjusting for all other factors were examined. A composite index of urbanicity was 267 developed from the UKBUMP built environment variables and expressed as:

268 Urbanicity zscore $_{\text {resid }}+$ zscore $_{\text {retail }}+$ zscore $_{P T}+$ zscore $_{\text {walkability }}$

269 where 'resid', 'retail' and 'PT' represent the density of residential housing units, retail 270 and public transport in units per square kilometer street catchment, while 'walkability' is 271 expressed in terms of street movement potential.

272 Post-hoc analyses further aimed to understand the behavioural mechanism behind the 273 observed associations between residential greenness and adiposity. Logistic regression 274 models explored the relationship between residential greenness and odds of using 275 active travel mode and doing more than 30 minutes walking for physical activity, 276 adjusting for all other factors.

277 Statistical analyses was performed with statistical software package Stata 11.4. Point 278 estimates ( $\beta$, risk ratio and odds ratio) and two-tailed 95\% confidence intervals have 279 been presented. Confidence intervals were estimated by bootstrapping except in 280 Poisson regression where robust estimator was employed.

\section{3. Results}

282 The characteristics of eligible study population ( $N=333183)$ have been presented in 283 Table 1, while Supplementary Table 1 compared the characteristics of the full UK 284 Biobank cohort and those included in the present study. The analytic sample remained 285 representative of the UK Biobank cohort. Overall, the mean BMI, WC and WBF was $28627.47 \mathrm{Kg} / \mathrm{m}^{2}\left(\mathrm{SD}=4.8 \mathrm{Kg} / \mathrm{m}^{2}\right), 90.35 \mathrm{~cm}(\mathrm{SD}=13.4 \mathrm{~cm})$ and $24.93 \mathrm{Kg}(9.6 \mathrm{Kg})$ 287 respectively, while $24.6 \%(\mathrm{~N}=82 \mathrm{024})$ of the participants were classified as obese. 
$21.3 \%$ of the participants used active transport mode for non-work travel trips and $46.3 \%$ did more than 30 minutes of walking. The study participants had a mean age of 56.5 years ( $S D=8.1$ years), while $54.6 \%$ were female. Current smokers accounted for $10.3 \%$ of the participants, while $24.1 \%, 5.6 \%$ and $5.2 \%$ had high blood pressure, cardiac disease and diabetes respectively.

[Insert Table 1]

Table 2 summarizes the distribution of residential greenness and other built environmental exposure variables. The mean residential greenness expressed in terms of NDVI index was $0.16(S D=0.17)$ with an interquartile range of 0.24 . Pearson's correlation coefficients between residential greenness and built environment exposure measures ranged from 0.03 to 0.23 . The variance inflation factors for all the association models were between 1.06 and 1.54 indicating a low level of collinearity.

[Insert Table 2]

Table 3 presents the characteristics of the analytic sample by distribution of residential greenness. The mean BMI in the first, second, third and fourth greenness quartiles were $27.62,27.46,27.38$ and $27.40 \mathrm{Kg} / \mathrm{m}^{2}$ respectively. The corresponding proportion of obese participants were $25.8 \%, 24.2 \%, 24.3 \%$ and $24.1 \%$ respectively.

[Insert Table 3]

Table 4 presents the results of regression models of association between residential green exposure and adiposity for $\mathrm{N}=333183$ participants with valid data across all variables. Residential greenness remained consistently significantly associated in all the three models (Model 1, 2, and 3) for BMI, WC, WBF and obesity with the beneficial effects of greenness being slightly strengthened across the minimally adjusted models (Model 1) to fully-adjusted models (Model 3). After adjusting for all other variables, an interquartile increment in NDVI greenness within a 500 metres catchment was associated with reduction of $0.123 \mathrm{Kg} / \mathrm{m}^{2}\left(95 \% \mathrm{Cl}:-0.14,-0.10 \mathrm{Kg} / \mathrm{m}^{2}\right)$ in $\mathrm{BMI}, 0.551 \mathrm{~cm}$ (95\% Cl: $-0.61,-0.50 \mathrm{~cm})$ in WC, and $0.138 \mathrm{Kg}$ in WBF $(95 \% \mathrm{Cl}:-0.18,-0.10 \mathrm{Kg})$ as well as a lower relative risk of obesity $(\mathrm{RR}=0.968,95 \% \mathrm{Cl}$ : $0.96,0.98)$. The protective 
316 effects of greenness upon adiposity outcomes remained consistent in the categorical

317 NDVI models (see Table 4).

318 [Insert Table 4]

319 Sub-group level analyses identified significant effect modification ( $p$-value for 320 interaction $<0.01$ ) by age, gender, degree of urbanicity and SES (measured as

321 Townsend index quintiles) was observed between exposure to NDVI green and all the 322 four markers of adiposity after adjusting for all other factors (presented in Figure 2).

$323 \quad$ [Insert Figure 2]

324 To test a physical activity-related mechanism, a set of models associating residential 325 green exposure and travel behaviour were developed (Table 5). Valid data on non-work 326 travel mode and duration of walking was available for a subset of 336682 and 281061 327 participants respectively. Subsequent to all adjustments, an interquartile increment in 328 NDVI greenness within $500 \mathrm{~m}$ dwelling catchment was significantly associated with 329 higher odds of using active travel mode (OR=1.093, 95\% Cl: $1.08,1.11)$ for non-work 330 trips and higher odds of doing more than 30 minutes walking (OR=1.039, 95\% Cl: 331 1.03,1.05). The results remained consistent in the categorical NDVI models.

$332 \quad[$ Insert Table 5]

333 Rerunning the models of adiposity and non-work travel with adjustments for duration of 334 walk in minutes (as a marker of physical activity) slightly modified the regression point 335 estimates and their corresponding confidence intervals (Supplementary Table 2).

336 Restricting analyses to only employed participants and further adjusting for work travel 337 mode attenuated the effects of residential green exposure (Supplementary Table 3).

338 Restricting analyses to a subset of healthy weight and overweight participants ( $N=251$

339 159; by excluding obese participants) attenuated the beneficial effects of green 340 exposures on weight outcomes pointing to the higher beneficial effects experienced by 341 participants in the more vulnerable weight categories (obese as compared to 342 overweight). An interquartile increment in NDVI greenness was associated with lower 343 relative risk of being overweight $(\mathrm{RR}=0.990,95 \% \mathrm{Cl}$ : 0.98, 0.99$)$. 


\section{Discussion}

In a very large and diverse UK-wide sample of adult population, residential greenness was independently associated with adiposity. The study is to the best of knowledge the largest of its kind and residential greenness, built environment and PM exposures were objectively modelled within catchments of individual participant's dwelling addresses, enabling substantial statistical power to detect effects.

The study reported an overall decrement of $0.123 \mathrm{Kg} / \mathrm{m}^{2}, 0.551 \mathrm{~cm}$ and $0.138 \mathrm{Kg}$ in BMI, WC and WBF respectively as well as a $3.2 \%$ lower risks of obesity accrued per interquartile increment in NDVI greenness. These corroborate findings from a few previous smaller scale studies on association between NDVI greenness and obesity (Bell et al. 2008; Pereira et al. 2013; Dadvand et al. 2014). This study focused on an UK-wide adult population sample (age spanning across 38-73 years with a mean of 56.5 years), given that this is a critical life stage for weight gain and development of obesity and related chronic disease. The results remained consistent across all the three markers of adiposity (BMI, WC and WBF) and remained robust subsequent to adjustments for SES, built environment and air pollution exposures. That the models remained sensitive to the inclusion of SES (Townsend's score) and wider built environment (terrain, retail, walkability, PM) underscores the necessity of a holistic approach that accounts for pertinent activity-influencing environmental exposures. The observed beneficial effects upon odds of using active travel mode for non-work trips and walking more than 30 minutes may point to a physical activity-related mechanism. These findings are consistent with prior studies largely small scale studies on the association between greenness and active travel; specifically walking (Sarkar et al. 2015b), cycling (Cole-Hunter et al. 2015) and physical activity (Almanza et al. 2012; Gong et al. 2014; McMorris et al. 2015).

Stratified models indicated differences in effects of green exposure across age-, gender-, urbanicity- and SES-subgroups. The gender differences in the association between green exposure and adiposity, especially the pronounced beneficial effects observed in female participants with respect to BMI, WBF and obesity outcomes correspond with previous reports and may be attributed to gender differences in 
374 perception, exposure and usage of green space within functional neighbourhoods (Roe 375 et al. 2013; Astell-Burt et al. 2014a). However, in the case of waist circumference, the 376 effects were more pronounced in male participants than female. The mean BMI and 377 WBF was $27.1 \mathrm{Kg} / \mathrm{m}^{2}\left(\mathrm{SD}=5.2 \mathrm{Kg} / \mathrm{m}^{2}\right)$ and $27.0 \mathrm{Kg}(\mathrm{SD}=10.1 \mathrm{Kg})$ for female and 27.9 $378 \mathrm{Kg} / \mathrm{m}^{2}\left(\mathrm{SD}=4.2 \mathrm{Kg} / \mathrm{m}^{2}\right)$ and $22.4 \mathrm{Kg}(\mathrm{SD}=8.2 \mathrm{Kg})$ respectively for male. The mean waist 379 circumference was $97.1 \mathrm{~cm}(\mathrm{SD}=11.2 \mathrm{~cm})$ for male and $84.8 \mathrm{~cm}(\mathrm{SD}=12.5 \mathrm{~cm})$ for female participants. That the beneficial effects of greenness were more pronounced and significant in the medium high and high quartiles of urbanicity points to their significant activity-promoting potential in high density city environments (Liu et al. 2007). Similarly, the beneficial effects of greenness were more pronounced in the higher quintiles of deprivation corresponding to lower SES groups. These point to the higher stressreleasing protective effects of residential greenness in deprived neighbourhoods and corroborate previous findings (de Vries et al., 2003; Mitchell and Popham, 2007, 2008). These results point to the need for more targeted policies for green space allocation and design that gives due credence spatial density profiles as well as the population-level characteristics of the residents.

\subsection{Interpretation}

The observed associations point to three potential underlying mechanisms; namely, physical, physiologic and psycho-social all corresponding to specific functional capacity of green. Firstly, a physical activity related mechanisms is plausible. Models of travel behaviour consistently indicated a significant beneficial association between residential green exposure and odds of using active transport for non-work trips as well as walking for more than 30 minutes. Any residential green space has an intrinsic activitypromoting potential associated with it. Natural forest and green spaces, parks, sports facilities and tree-lined streets may thus directly act as recreational and physical activity facilities with associated increments in physical activity accrued (Bedimo-Rung et al. 2005; Kaczynski and Henderson 2007; Björk et al. 2008; White et al. 2016). However,

401 physical activity is not the only pathway linking green exposure and adiposity.

402 Physiologically, the stress-releasing pathway is very important (Halonen et al. 2014). In 403 an urban setting, residential green constitute therapeutic stress-releasing environments 404 (Grahn and Stigsdotter 2003; Hartig et al. 2003). Reductions in stress levels associated 
with green exposures (Nielsen and Hansen 2007) and have been measured through biomarkers such as salivary cortisol, amylase (Ward Thompson et al. 2012; Beil and Hanes 2013) and telomere length (Woo et al. 2009). Such stress-releasing exposures promote healthy weight maintenance by facilitating active travel in the form of walking and exercise as well as recreation. Previously, studies have already established the positive associations between stress and weight gain (Block et al. 2009; Harding et al. 2014). Other physiologic benefits include better health outcomes including longevity (Takano et al. 2002), and cardio-metabolic health (Mitchell and Popham 2008; Pereira et al. 2012; Bodicoat et al. 2014). Lastly, the intangible salutogenic potential associated with a residential green may help constitute a better perception of residential environment. It can thus act as spaces for social interaction facilitating neighbourhood cohesion and sense of community (Kweon et al. 1998; Maas et al. 2009; Arnberger and Eder 2012; Kaźmierczak 2013) and improved mental health (Barton and Pretty 2010; Alcock et al. 2014; Astell-Burt et al. 2014b). All these factors together promote active travel and walking behaviour and corresponding increments in physical activity.

\subsection{Strengths and limitations}

The strengths of the study include high quality data of unprecedented size ( $>300 k)$; geographical coverage and diversity; sub-group level analyses; application of objective measures of urban greenness; extensive adjustments for activity-influencing exposure metrics of built environment, air pollution and other confounding. The UK Biobank cohort health data underwent considerable central quality control. The NDVI index employed in the present study represent a highly characterized measure of residential green exposure. Conventional measures of urban green such park access derived from land use database are often coarse and fail to capture small scale variability in vegetation, private gardens and street trees. In contrast, the NDVI vegetation index not only constitutes a more objective measure of green exposure (both density and quality) but can also act as metrics capturing the intangible salutogenic potential of residential environment and therefore it's influence on behaviour and weight outcomes. The NDVI index was generated from a multispectral Bluesky colour infrared imagery of 0.50-metre resolution captured during aerial photography with the Vexcel UltraCamD and the Leica ADS4 (having a spatial accuracy of $1 \mathrm{~m}$ ). Such a precise data capture method implied 
that the study was able to overcome the limitations inherent in most prior studies using satellite remote sensing data, whose quality is often limited by low resolution (approximately $30 \mathrm{~m}$ resolution), cloud cover and atmospheric distortions (Sarkar et al. 2015b). Adjustments for activity-influencing built environment measured around individual residential catchments enhanced the reliability of the models. A highly detailed metrics of walkability expressed in terms of betweenness (through-movement potential) measured at the level of street network segments meant intuitive linkages urban morphology and design, walking and health could be practically established. Similarly, adjustments for a wide array of individual-level variables pertaining to sociodemographics, lifestyle and comorbidities ensured extensive adjustments for confounding. Most residential green - health studies tended to employ body mass index as the outcome measure with virtually no studies focusing on other biomarkers of body adiposity (distribution and mass), especially waist circumference and whole body fat. The present analyses employs a more holistic and objective definition of adiposity (Flegal et al. 2009) and the effects of residential green upon the three measures showed a near similar trend.

The study is however limited by its cross sectional design. Causal inferences can't be made with confidence. The role of geographic life environments and effects of cumulative exposures to green environment upon weight outcomes require further exploration. Neighbourhood self-selection may have influenced the reported results. Obese participants may have selectively migrated to greener areas leading to underestimation of the effects of residential green on obesity prevalence. Nonetheless, the effects of migration were less likely as mean length of stay in the current dwelling address was 17.5 years indicating considerable degree of residential stability. It was similar for both non-obese (17.3 years) and obese (17.8 years) participants and addition of duration of stay in the models didn't produce any material effects upon the observed associations. Temporal mismatch is another issue associated with cross-sectional cohort studies when data are collected at different time points (Buzzelli and Su 2006). Adiposity measures and most of the individual-level confounders were assessed over the baseline phase of UK biobank (2006-2010) for the established cohort participants already residing in specific dwelling locations. The green exposure measures of 
467 UKBUMP were modelled over the same period to avoid temporal mismatch as much as

468 possible; however the study lacked detailed information on the dates of adiposity measurements at an individual participant-level to establish if the adiposity outcome measurements preceded or followed exposure measurements. Future investigations upon accumulated follow-up data of full UK Biobank cohort should focus on longitudinal analyses to isolate potential causal pathways. As prospective data gets accumulated over time, further studies focusing on natural experiments can be feasible through analyses of a sub-set of cohort participants moving to new addresses, thereby associating changes in adiposity with changes green exposures prior and subsequent to such moves. The use of self-reported data on travel mode and duration of walking is subject to individual bias. Future studies employing accelerometry sub-sample data from UK Biobank would enable a more objective method for quantifying walking and physical activity. Response bias may have affected the degree of generalizability of the observed association; the UK Biobank study could attain a response rate of $5.5 \%$. Nonetheless, it doesn't imply significant loss of generalizability of these findings, given the sufficiently large sample size, existing diversity in the sample characteristics as well as the heterogeneity of environmental exposures as discussed earlier (Collins 2012). Most of the built environment measures showed significant variability across space and population groups.

\subsection{Conclusion}

In conclusion, residential green exposure was beneficially associated with markers of adiposity in a cross sectional UK Biobank population sample of unprecedented size and diversity. Effect modification models identified underlying sensitivities in the associations to population characteristics, urbanicity and SES. With the rapid urban expansion, more research is needed to understand optimal parameters for green allocation and design (in terms of its design, size and distribution, connectivity characteristics) for it to act as upstream-level public health intervention ameliorating the negative health externalities of obesogenic urban environments. The effectiveness of such public health interventions will also entail an empirical understanding of specific causal pathways 
496 linking exposure to green, adiposity and health through further research based on a 497 prospective data.

498

499

500

501

502

503

504

505

506

507

508

509

510

511

512

513

514

515

516

517

518

519

520

521

522

523

524

525

526

527

\section{Ethics statement}

UK Biobank has received ethical approvals from the North West Multi-centre Research Ethics Committee (MREC), the Community Health Index Advisory Group (CHIAG), the Patient Information Advisory Group (PIAG) and National Health Service National Research Ethics Service. Permission to use the UK Biobank resource for the research was approved by UK Biobank Access sub-committee (approved research application no. 11730).

\section{Acknowledgement}

The research has been conducted using UK Biobank resource. The study was funded by the University of Hong Kong's URC PDF-Research Assistant Professorship Grant; UK Biobank seed grant; and UK Economic \& Social Research Council's Transformative Research grant [ES/L003201/1]. The author thanks the UK Ordnance Survey, UK's National Mapping Agency and MIMAS (University of Manchester) for providing access to its UK-wide spatial data for use in this study.

\section{References}

Alcock, I.; White, M.P.; Wheeler, B.W.; Fleming, L.E.; Depledge, M.H. Longitudinal effects on mental health of moving to greener and less green urban areas. Environmental Science \& Technology 2014;48:1247-1255

Allen, N.E.; Sudlow, C.; Peakman, T.; Collins, R. UK biobank data: come and get it. Science Translational Medicine 2014;6:224ed224

Almanza, E.; Jerrett, M.; Dunton, G.; Seto, E.; Pentz, M.A. A study of community design, greenness, and physical activity in children using satellite, GPS and accelerometer data. Health \& Place 2012;18:46-54

Arnberger, A.; Eder, R. The influence of green space on community attachment of urban and suburban residents. Urban Forestry \& Urban Greening 2012;11:41-49

Astell-Burt, T.; Feng, X.; Kolt, G. Greener neighborhoods, slimmer people? Evidence from 246 920 Australians. International journal of obesity 2014a;38:156-159

Astell-Burt, T.; Mitchell, R.; Hartig, T. The association between green space and mental health varies across the lifecourse. A longitudinal study. Journal of Epidemiology and Community Health 2014b;68:578-583 
Barton, J.; Pretty, J. What is the best dose of nature and green exercise for improving mental health? A multi-study analysis. Environmental Science \& Technology 2010;44:3947-3955

Bedimo-Rung, A.L.; Mowen, A.J.; Cohen, D.A. The significance of parks to physical activity and public health: a conceptual model. American Journal of Preventive Medicine 2005;28:159-168

Beil, K.; Hanes, D. The influence of urban natural and built environments on physiological and psychological measures of stress-A pilot study. International Journal of Environmental Research and Public Health 2013;10:1250-1267

Bell, J.F.; Wilson, J.S.; Liu, G.C. Neighborhood greenness and 2-year changes in body mass

index of children and youth. American Journal of Preventive Medicine 2008;35:547-553

Bhaskaran, K.; Douglas, I.; Forbes, H.; dos-Santos-Silva, I.; Leon, D.A.; Smeeth, L. Body-mass index and risk of 22 specific cancers: a population-based cohort study of $5 \cdot 24$ million UK adults. The Lancet 2014;384:755-765

Björk, J.; Albin, M.; Grahn, P.; Jacobsson, H.; Ardö, J.; Wadbro, J.; Östergren, P.-O.; Skärbäck, E. Recreational values of the natural environment in relation to neighbourhood satisfaction, physical activity, obesity and wellbeing. Journal of Epidemiology and Community Health 2008;62:e2-e2

Block, J.P.; He, Y.; Zaslavsky, A.M.; Ding, L.; Ayanian, J.Z. Psychosocial stress and change in weight among US adults. American Journal of Epidemiology 2009;170:181-192

International Journal of Behavioral Nutrition and Physical Activity 2014;11:40

Bodicoat, D.H.; O'Donovan, G.; Dalton, A.M.; Gray, L.J.; Yates, T.; Edwardson, C.; Hill, S.; Webb, D.R.; Khunti, K.; Davies, M.J. The association between neighbourhood greenspace and type 2 diabetes in a large cross-sectional study. BMJ Open 2014;4:e006076

Brownson, R.C.; Hoehner, C.M.; Day, K.; Forsyth, A.; Sallis, J.F. Measuring the built environment for physical activity: state of the science. American Journal of Preventive Medicine 2009;36:S99-S123. e112

Buzzelli, M.; Su, J. Multi-level modelling in health research: a caution and rejoinder on temporally mismatched data. Social Science \& Medicine 2006;62:1215-1218

Chiaradia, A.J.; Crispin, C.; Webster, C. sDNA: A software for spatial design network analysis. Specifications. 2012. http://www.cardiff.ac.uk/sdna/

Cole-Hunter, T.; Donaire-Gonzalez, D.; Curto, A.; Ambros, A.; Valentin, A.; Garcia-Aymerich, J.; Martínez, D.; Braun, L.; Mendez, M.; Jerrett, M. Objective correlates and determinants of bicycle commuting propensity in an urban environment. Transportation Research Part D: Transport and Environment 2015;40:132-143

Collins, R. What makes UK Biobank special? The Lancet 2012;379:1173-1174

Cummings, $\mathrm{P}$. The relative merits of risk ratios and odds ratios. Archives of Pediatrics \& Adolescent Medicine 2009;163:438-445 
564

565

566

567

568

569

570

571

572

573

574

575

576

577

578

579

580

581

582

583

584

585

586

587

588

589

590

591

592

593

594

595

596

597

598

599

600

601

Cummins, S.; Fagg, J. Does greener mean thinner? Associations between neighbourhood greenspace and weight status among adults in England. International Journal of Obesity 2012;36:1108-1113

Dadvand, P.; Villanueva, C.M.; Font-Ribera, L.; Martinez, D.; Basagaña, X.; Belmonte, J.; Vrijheid, M.; Grazuleviciene, R.; Kogevinas, M.; Nieuwenhuijsen, M.J. Risks and benefits of green spaces for children: a cross-sectional study of associations with sedentary behavior, obesity, asthma, and allergy. Environmental Health Perspectives 2014;122:1329

de Vries, S.; Verheij, R.A.; Groenewegen, P.P.; Spreeuwenberg, P. Natural environments Healthy environments? An exploratory analysis of the relationship between greenspace and health. Environment and Planning A 2003;35:1717-1731

Depledge, M.H.; Stone, R.J.; Bird, W.J. Can natural and virtual environments be used to promote improved human health and wellbeing? Environmental Science \& Technology 2011;45:4660-4665

Eeftens, M.; Beelen, R.; de Hoogh, K.; Bellander, T.; Cesaroni, G.; Cirach, M.; Declercq, C.; Dedele, A.; Dons, E.; de Nazelle, A. Development of land use regression models for PM2. 5, PM2. 5 absorbance, PM10 and PMcoarse in 20 European study areas; results of the ESCAPE project. Environmental Science \& Technology 2012;46:11195-11205

Flegal, K.M.; Graubard, B.I.; Williamson, D.F.; Gail, M.H. Cause-specific excess deaths associated with underweight, overweight, and obesity. JAMA 2007;298:2028-2037

Flegal, K.M.; Shepherd, J.A.; Looker, A.C.; Graubard, B.I.; Borrud, L.G.; Ogden, C.L.; Harris, T.B.; Everhart, J.E.; Schenker, N. Comparisons of percentage body fat, body mass index, waist circumference, and waist-stature ratio in adults. The American Journal of Clinical Nutrition 2009;89:500-508

Gong, Y.; Gallacher, J.; Palmer, S.; Fone, D. Neighbourhood green space, physical function and participation in physical activities among elderly men: the Caerphilly Prospective study. International Journal of Behavioral Nutrition and Physical Activity 2014;11:40

Grahn, P.; Stigsdotter, U.A. Landscape planning and stress. Urban Forestry \& Urban Greening 2003;2:1-18

Hartig, T.; Evans, G.W.; Jamner, L.D.; Davis, D.S.; Gärling, T. Tracking restoration in natural and urban field settings. Journal of Environmental Psychology 2003;23:109-123

Harding, J.L.; Backholer, K.; Williams, E.D.; Peeters, A.; Cameron, A.J.; Hare, M.J.; Shaw, J.E.; Magliano, D.J. Psychosocial stress is positively associated with body mass index gain over 5 years: evidence from the longitudinal AusDiab study. Obesity 2014;22:277-286

Halonen, J.I.; Kivimäki, M.; Pentti, J.; Stenholm, S.; Kawachi, I.; Subramanian, S.; Vahtera, J. Green and blue areas as predictors of overweight and obesity in an 8-year follow-up study. Obesity 2014;22:1910-1917

Hartig, T.; Mitchell, R.; De Vries, S.; Frumkin, H. Nature and health. Annual Review of Public Health 2014;35:207-228 
602

606

608

610

James, P.; Banay, R.F.; Hart, J.E.; Laden, F. A review of the health benefits of greenness. Current Epidemiology Reports 2015;2:131-142

Kaczynski, A.T.; Henderson, K.A. Environmental correlates of physical activity: a review of evidence about parks and recreation. Leisure Sciences 2007;29:315-354

Kaźmierczak, A. The contribution of local parks to neighbourhood social ties. Landscape and Urban Planning 2013;109:31-44

Kweon, B.-S.; Sullivan, W.C.; Wiley, A.R. Green common spaces and the social integration of inner-city older adults. Environment and Behavior 1998;30:832-858

Lachowycz, K.; Jones, A. Greenspace and obesity: a systematic review of the evidence.

Obesity Reviews 2011;12:e183-e189

Leal, C.; Chaix, B. The influence of geographic life environments on cardiometabolic risk factors: a systematic review, a methodological assessment and a research agenda. Obesity Reviews 2011;12:217-230

Liu, G.C.; Wilson, J.S.; Qi, R.; Ying, J. Green neighborhoods, food retail and childhood overweight: differences by population density. American Journal of Health Promotion 2007;21:317-325

Loughner, C.P.; Allen, D.J.; Zhang, D.-L.; Pickering, K.E.; Dickerson, R.R.; Landry, L. Roles of urban tree canopy and buildings in urban heat island effects: Parameterization and preliminary results. Journal of Applied Meteorology and Climatology 2012;51:1775-1793

Maas, J.; Van Dillen, S.M.; Verheij, R.A.; Groenewegen, P.P. Social contacts as a possible mechanism behind the relation between green space and health. Health \& Place 2009;15:586595

Maas, J.; Verheij, R.A.; Spreeuwenberg, P.; Groenewegen, P.P. Physical activity as a possible mechanism behind the relationship between green space and health: a multilevel analysis. BMC Public Health 2008;8:206

McMorris, O.; Villeneuve, P.J.; Su, J.; Jerrett, M. Urban greenness and physical activity in a national survey of Canadians. Environmental Research 2015;137:94-100

Mitchell, R.; Popham, F. Greenspace, urbanity and health: relationships in England. Journal of Epidemiology and Community Health 2007;61:681-683

Mitchell, R.; Popham, F. Effect of exposure to natural environment on health inequalities: an observational population study. The Lancet 2008;372:1655-1660

Mowafi, M.; Khadr, Z.; Bennett, G.; Hill, A.; Kawachi, I.; Subramanian, S. Is access to neighborhood green space associated with BMI among Egyptians? A multilevel study of Cairo neighborhoods. Health \& Place 2012;18:385-390

Nielsen, T.S.; Hansen, K.B. Do green areas affect health? Results from a Danish survey on the use of green areas and health indicators. Health \& Place 2007;13:839-850 
Nowak, D.J.; Crane, D.E.; Stevens, J.C. Air pollution removal by urban trees and shrubs in the United States. Urban Forestry \& Urban Greening 2006;4:115-123

640 Ord, K.; Mitchell, R.; Pearce, J. Is level of neighbourhood green space associated with physical activity in green space? International Journal of Behavioral Nutrition and Physical Activity 2013;10:127

643 Pereira, G.; Christian, H.; Foster, S.; Boruff, B.J.; Bull, F.; Knuiman, M.; Giles-Corti, B. The association between neighborhood greenness and weight status: an observational study in Perth Western Australia. Environmental Health 2013;12:49

646 Pereira, G.; Foster, S.; Martin, K.; Christian, H.; Boruff, B.J.; Knuiman, M.; Giles-Corti, B. The association between neighborhood greenness and cardiovascular disease: an observational study. BMC Public Health 2012;12:466

Potestio, M.L.; Patel, A.B.; Powell, C.D.; McNeil, D.A.; Jacobson, R.D.; McLaren, L. Is there an association between spatial access to parks/green space and childhood overweight/obesity in Calgary, Canada? International Journal of Behavioral Nutrition and Physical Activity 2009;6:77

Prince, S.A.; Kristjansson, E.A.; Russell, K.; Billette, J.-M.; Sawada, M.; Ali, A.; Tremblay, M.S.; Prud'homme, D. A multilevel analysis of neighbourhood built and social environments and adult self-reported physical activity and body mass index in Ottawa, Canada. International Journal of Environmental Research and Public Health 2011;8:3953-3978

Rhew, I.C.; Vander Stoep, A.; Kearney, A.; Smith, N.L.; Dunbar, M.D. Validation of the normalized difference vegetation index as a measure of neighborhood greenness. Annals of Epidemiology 2011;21:946-952

Roe, J.J.; Thompson, C.W.; Aspinall, P.A.; Brewer, M.J.; Duff, E.I.; Miller, D.; Mitchell, R.; Clow, A. Green space and stress: Evidence from cortisol measures in deprived urban communities. International Journal of Environmental Research and Public Health 2013;10:4086-4103 activity, obesity, and cardiovascular disease. Circulation 2012;125:729-737

664 Sarkar, C.; Gallacher, J.; Webster, C. Built environment configuration and change in body mass index: The Caerphilly Prospective Study (CaPS). Health \& Place 2013a;19:33-44

668 Sarkar, C.; Webster, C. Healthy Cities of Tomorrow: the Case for Large Scale Built 669 Environment-Health Studies. Journal of Urban Health 2017; 94(1):4-19

670 Sarkar, C.; Webster, C.; Gallacher, J. Healthy Cities: Public Health Through Urban Planning 671 ed^eds. Cheltenham, UK: Edward Elgar Publishing; 2014

672 Sarkar, C.; Webster, C.; Gallacher, J. UK Biobank Urban Morphometric Platform (UKBUMP)-a 673 nationwide resource for evidence-based healthy city planning and public health interventions.

674 Annals of GIS 2015a;21:135-148 
690

691

692

693

694

695

696

697

698

699

700

701

702

703

704

705
Sarkar, C.; Webster, C.; Pryor, M.; Tang, D.; Melbourne, S.; Zhang, X.; Jianzheng, L. Exploring associations between urban green, street design and walking: Results from the Greater London boroughs. Landscape and Urban Planning 2015b;143:112-125

Sudlow, C.; Gallacher, J.; Allen, N.; Beral, V.; Burton, P.; Danesh, J.; Downey, P.; Elliott, P.; Green, J.; Landray, M. UK biobank: an open access resource for identifying the causes of a wide range of complex diseases of middle and old age. PLOS Medicine 2015;12:e1001779

Swinburn, B.A.; Sacks, G.; Hall, K.D.; McPherson, K.; Finegood, D.T.; Moodie, M.L.; Gortmaker, S.L. The global obesity pandemic: shaped by global drivers and local environments. The Lancet 2011;378:804-814

Takano, T.; Nakamura, K.; Watanabe, M. Urban residential environments and senior citizens' longevity in megacity areas: the importance of walkable green spaces. Journal of Epidemiology and Community Health 2002;56:913-918

Tobias, D.K.; Pan, A.; Jackson, C.L.; O'Reilly, E.J.; Ding, E.L.; Willett, W.C.; Manson, J.E.; Hu, F.B. Body-mass index and mortality among adults with incident type 2 diabetes. New England Journal of Medicine 2014;370:233-244

Villeneuve, P.J.; Jerrett, M.; Su, J.G.; Burnett, R.T.; Chen, H.; Wheeler, A.J.; Goldberg, M.S. A cohort study relating urban green space with mortality in Ontario, Canada. Environmental Research 2012;115:51-58

Ward Thompson, C.; Roe, J.; Aspinall, P.; Mitchell, R.; Clow, A.; Miller, D. More green space is linked to less stress in deprived communities: Evidence from salivary cortisol patterns.

Landscape and Urban Planning 2012;105:221-229

White, M.; Elliott, L.; Taylor, T.; Wheeler, B.; Spencer, A.; Bone, A.; Depledge, M.; Fleming, L. Recreational physical activity in natural environments and implications for health: A population based cross-sectional study in England. Preventive Medicine 2016;91:383-388

Wolch, J.; Jerrett, M.; Reynolds, K.; McConnell, R.; Chang, R.; Dahmann, N.; Brady, K.; Gilliland, F.; Su, J.G.; Berhane, K. Childhood obesity and proximity to urban parks and recreational resources: a longitudinal cohort study. Health \& Place 2011;17:207-214

Woo, J.; Tang, N.; Suen, E.; Leung, J.; Wong, M. Green space, psychological restoration, and telomere length. The Lancet 2009;373:299-300 


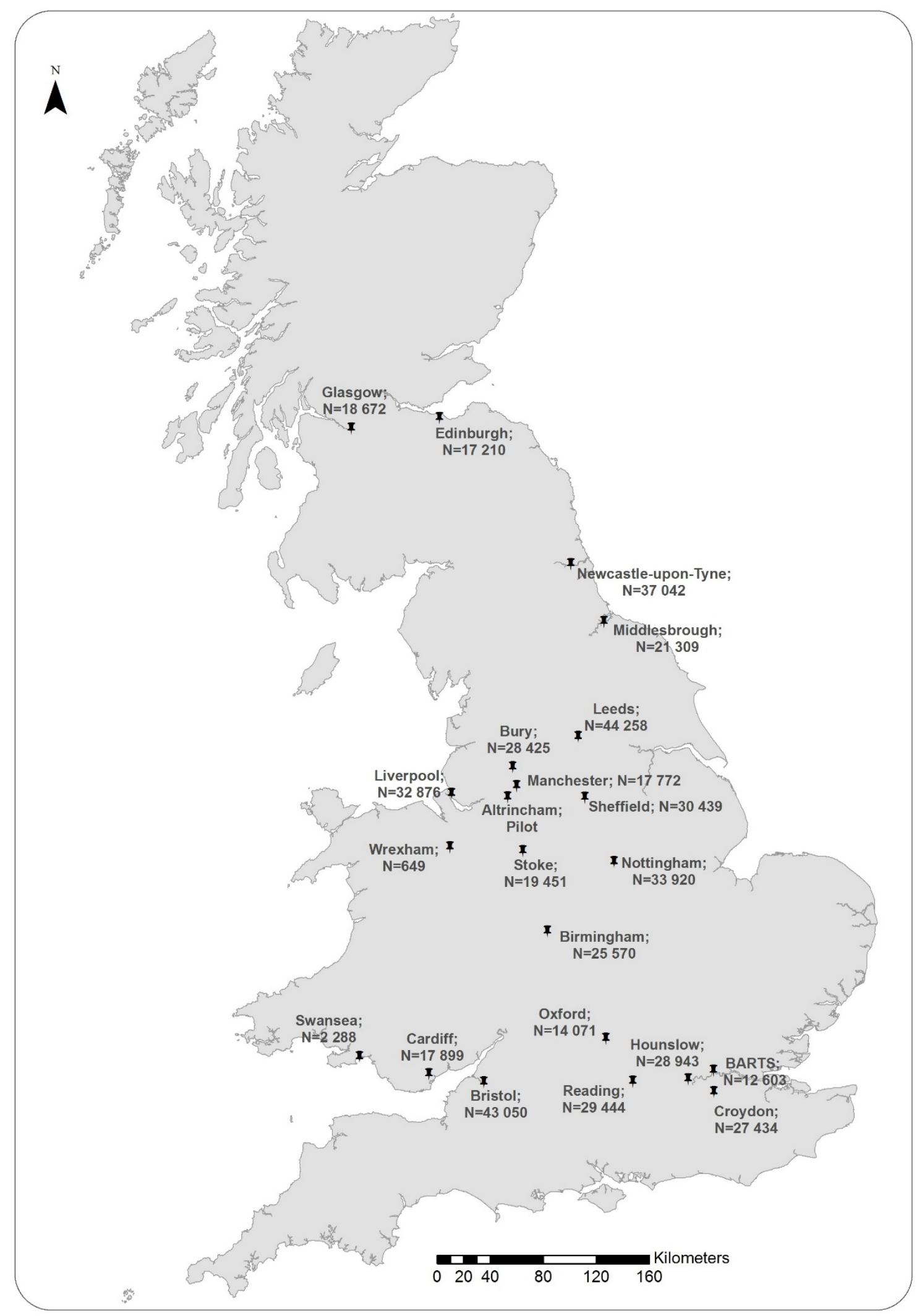

Figure 1. Location of UK Biobank collection centres with the number of participants. 


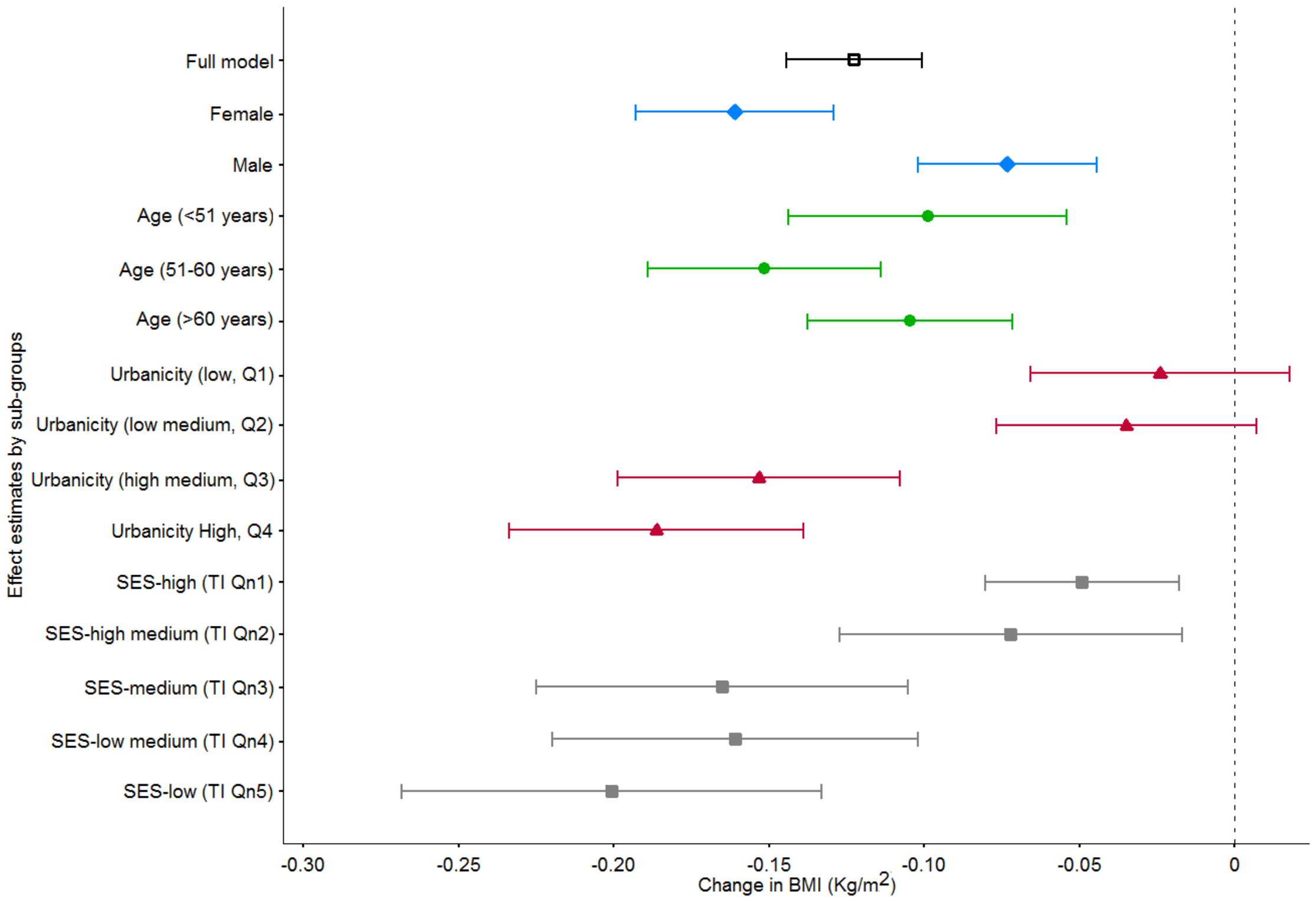

Figure $2 a$ 


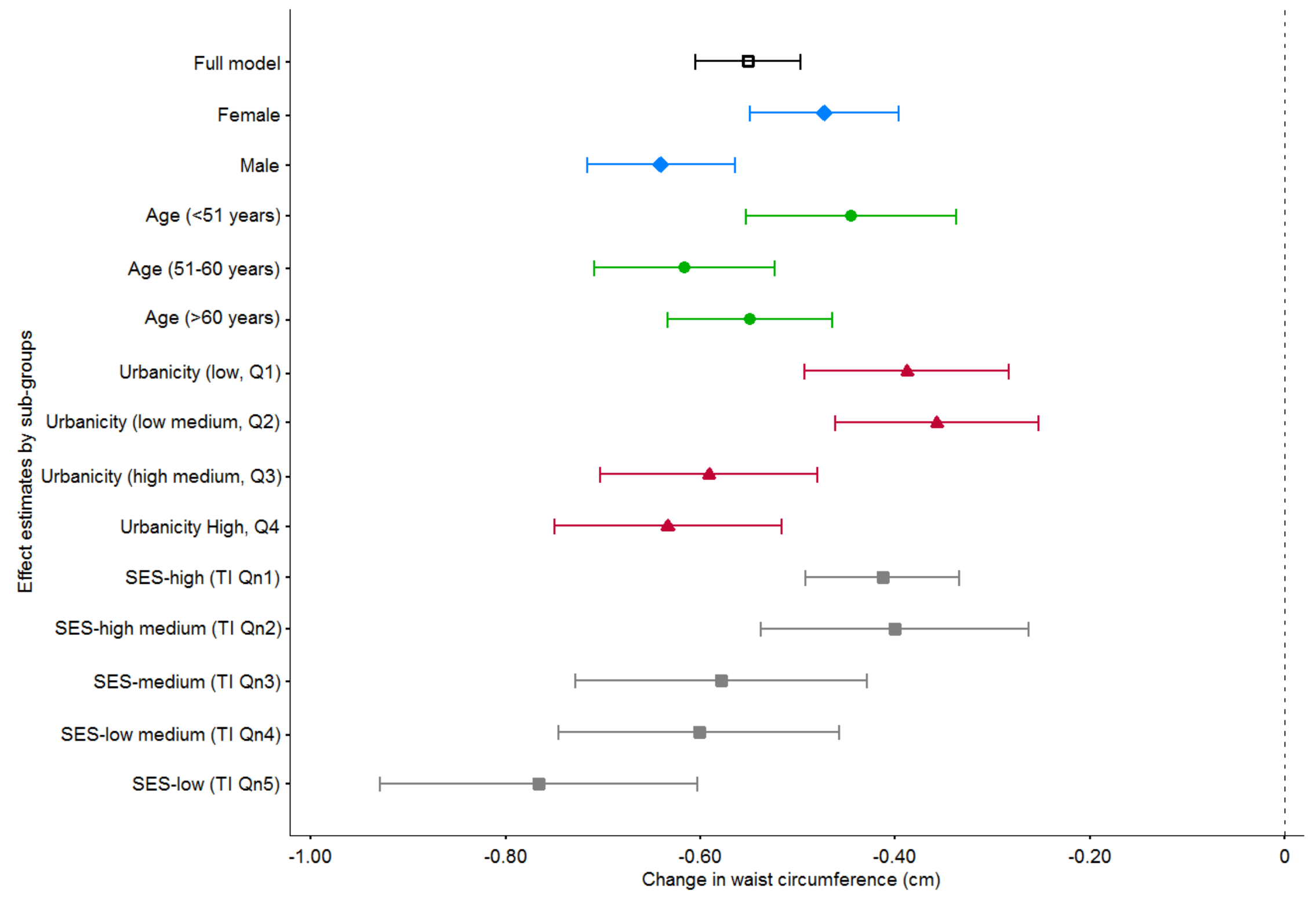

Figure $2 b$ 


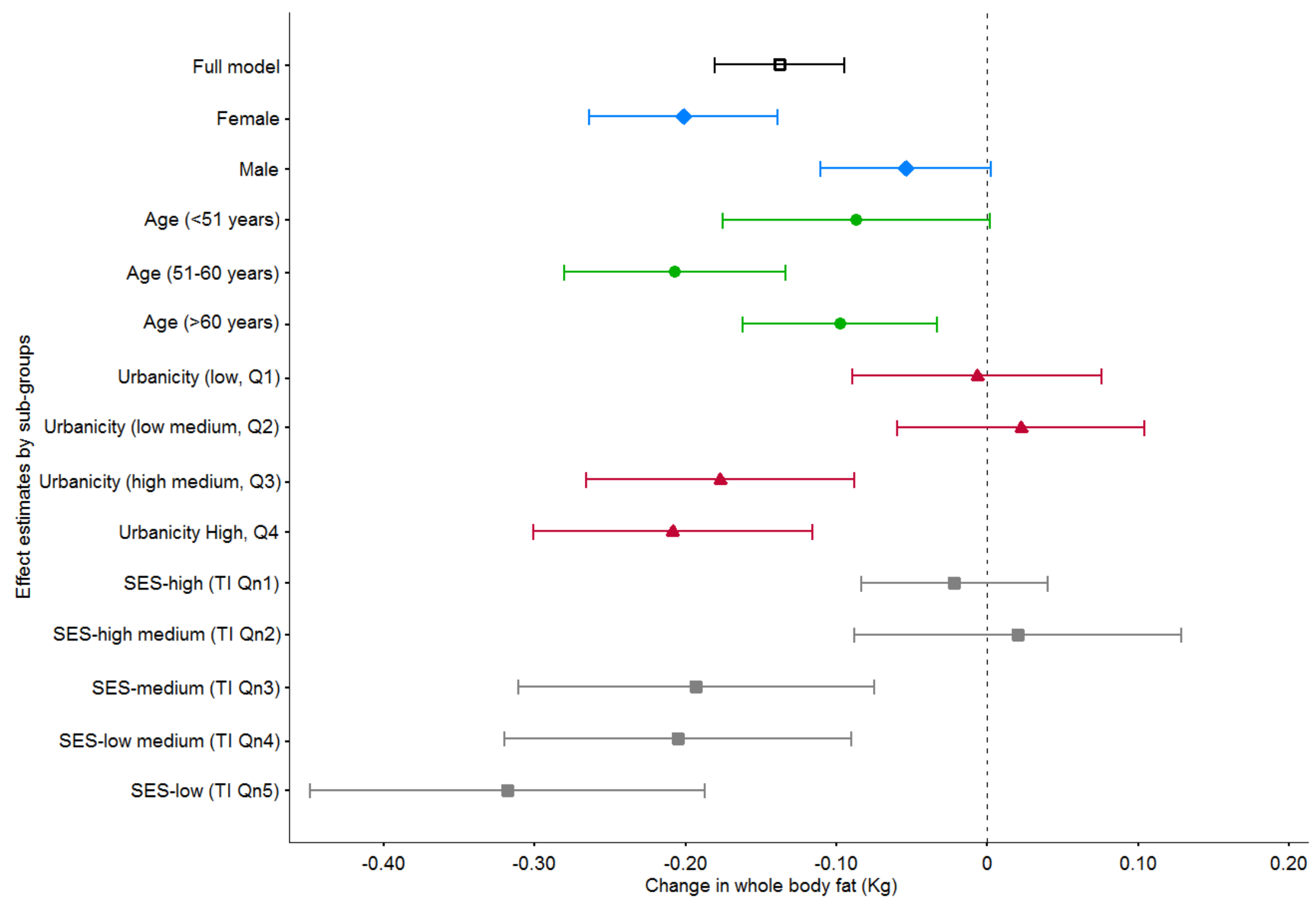

Figure $2 c$ 


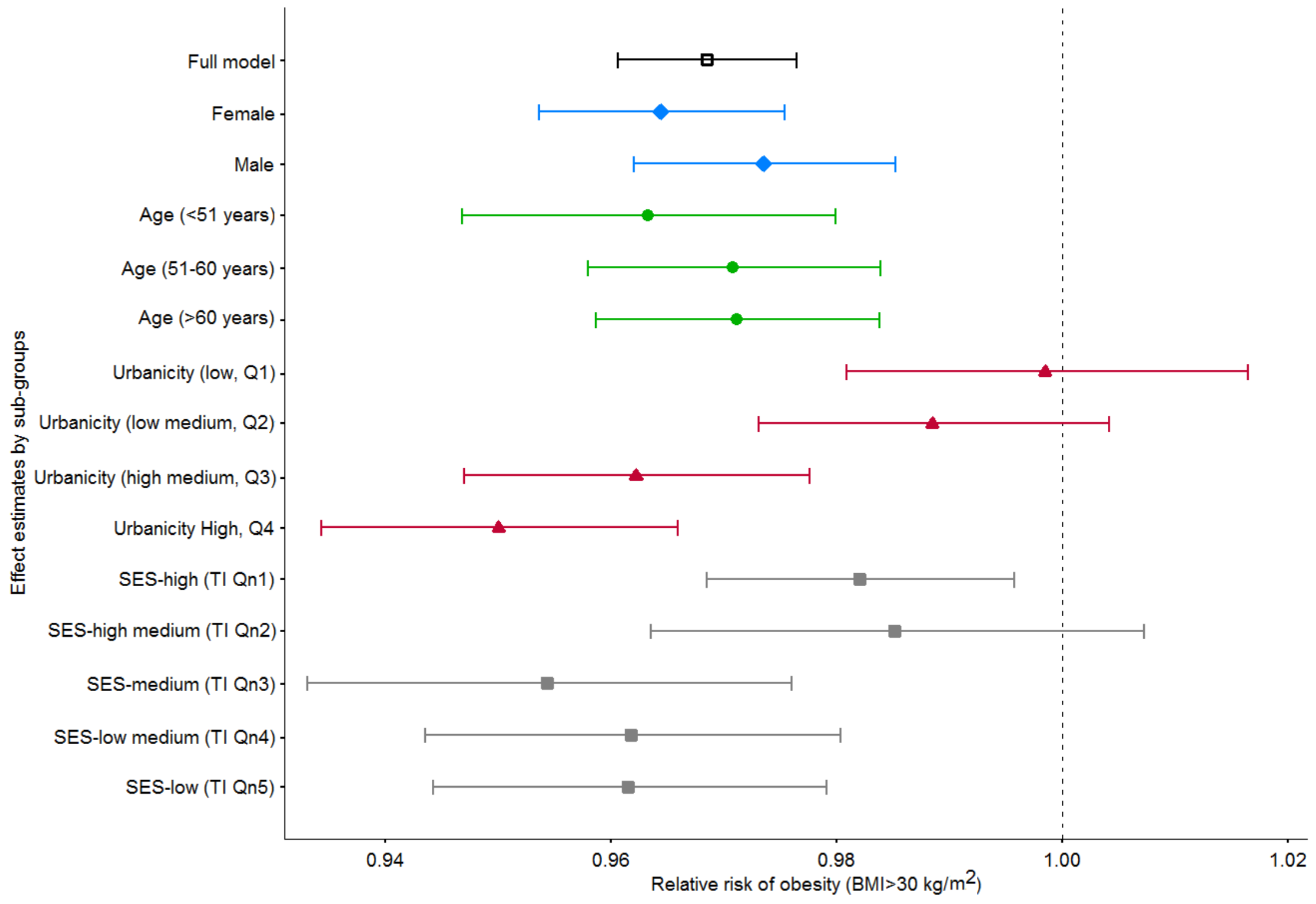

Figure $2 d$ 
Figure 2a-d. Association between residential green and adiposity; effect modification by gender, age, urbanicity and SES adjusting for all other factors.

Bars show $95 \%$ confidence intervals.

Q1, Q2, Q3 and Q4 represent 1 $1^{\text {st }}, 2^{\text {nd }}, 3^{\text {rd }}, 4^{\text {th }}$ quartiles of index of urbanicity; Qn1, Qn2, Qn3, Qn4 and Qn5 represent $1^{\text {st }}, 2^{\text {nd }}, 3^{\text {rd }}, 4^{\text {th }}$, $5^{\text {th }}$ quintiles of Townsend Index $(\mathrm{TI})$ respectively. 
Tables

Table 1. Characteristics of UK Biobank participants $(\mathrm{N}=333$ 183).

\begin{tabular}{|c|c|c|c|}
\hline Participant characteristics & $\begin{array}{c}\text { Not obese } \\
\left(\mathrm{BMl}<30 \mathrm{Kg} / \mathrm{m}^{2}\right) \\
251159\end{array}$ & $\begin{array}{c}\text { Obese } \\
\left(\mathrm{BMI} \geq 30 \mathrm{~kg} / \mathrm{m}^{2}\right) \\
82024\end{array}$ & Overall \\
\hline \multicolumn{4}{|l|}{ Mean (SD) } \\
\hline $\mathrm{BMI}\left(\mathrm{Kg} / \mathrm{m}^{2}\right)$ & $25.35(2.6)$ & $33.94(3.9)$ & $27.47(4.8)$ \\
\hline Waist circumference (cm) & $85.57(10.3)$ & $105.0(11.0)$ & $90.35(13.4)$ \\
\hline Whole body fat mass (Kg) & $21.12(6.0)$ & $36.57(9.1)$ & $24.93(9.6)$ \\
\hline Duration of walk (minutes) ${ }^{*}$ & $52.03(48.5)$ & $49.71(48.7)$ & $51.48(48.5)$ \\
\hline Age (years) & $56.43(8.2)$ & $56.86(7.9)$ & $56.5(8.1)$ \\
\hline SES (Townsend index) & $-1.47(2.9)$ & $-0.91(3.2)$ & $-1.33(3.0)$ \\
\hline \multicolumn{4}{|l|}{$\mathrm{N}(\%)$} \\
\hline Gender: Female & $138824(55.3)$ & $43262(52.7)$ & $182086(54.6)$ \\
\hline Male & $112335(44.7)$ & $38762(47.3)$ & $151097(45.4)$ \\
\hline Ethnicity: British & 225025 (89.6) & $73148(89.2)$ & $298173(89.5)$ \\
\hline Others & $26134(10.4)$ & $8876(10.8)$ & $35010(10.5)$ \\
\hline Education: None & $39225(15.6)$ & $18385(22.4)$ & $57610(17.3)$ \\
\hline College or University degree & $85628(34.1)$ & $19707(24)$ & 105335 (31.6) \\
\hline O levels/GCSEs/CSEs & $69287(27.6)$ & $24277(29.6)$ & $93564(28.1)$ \\
\hline A levels/AS levels & $28369(11.3)$ & $8335(10.2)$ & $36704(11)$ \\
\hline NVQ/HND/HNC/Other professional & $28650(11.4)$ & $11320(13.8)$ & $39970(12)$ \\
\hline Employment status: Employed & $147436(58.7)$ & $45367(55.3)$ & 192803 (57.9) \\
\hline Retired & $84885(33.8)$ & $27997(34.1)$ & $112882(33.9)$ \\
\hline Unemployed, home maker, others & $18838(7.5)$ & $8660(10.6)$ & $27498(8.2)$ \\
\hline Smoking status: Nonsmoker & $140273(55.8)$ & $41882(51.1)$ & $182155(54.7)$ \\
\hline Previous smoker & $84303(33.6)$ & 32461 (39.6) & $116764(35)$ \\
\hline $\begin{array}{l}\text { Current smoker } \\
\text { Non-work transport mode }{ }^{* *} \text { : }\end{array}$ & $26583(10.6)$ & $7681(9.4)$ & $34264(10.3)$ \\
\hline Walk/ cycle/ public transport & $55349(21.8)$ & $16192(19.6)$ & $71541(21.3)$ \\
\hline Car/ motor vehicle & $198756(78.2)$ & $66385(80.4)$ & $265141(78.7)$ \\
\hline Vascular problems: None & $190014(75.7)$ & $44335(54.1)$ & $234349(70.3)$ \\
\hline High blood pressure & $49684(19.8)$ & $30436(37.1)$ & $80120(24.1)$ \\
\hline Heart attack/ angina/ stroke & $11461(4.6)$ & $7253(8.8)$ & $18714(5.6)$ \\
\hline Diabetes: None & $243221(96.8)$ & $72728(88.7)$ & 315949 (94.8) \\
\hline Yes & 7938 (3.2) & 9296 (11.3) & $17234(5.2)$ \\
\hline
\end{tabular}

${ }^{*} \mathrm{~N}=281061 ;{ }^{* *} \mathrm{~N}=336682$ 
Table 2. Summary of environmental exposure variables

\begin{tabular}{lcccccc}
\hline Environmental exposure & Mean \pm SD & Minimum & P25 & P50 & P75 & Maximum \\
\hline & & & & & & \\
& & & & & & \\
Residential greenness (mean NDVI, 500m) & $0.16 \pm 0.17$ & -0.26 & 0.04 & 0.17 & 0.28 & 0.70 \\
Terrain variability (1 SD) & $2.96 \pm 1.62$ & 0.14 & 1.74 & 2.71 & 3.85 & 15.05 \\
Walkability (betweeness R800) & $4.70 \times 10^{6} \pm$ & & & & & \\
Density retail (units $\left./ \mathrm{Km}^{2}\right)$ & $5.59 \times 10^{6}$ & 5076.2 & $8.8 \times 10^{5}$ & $2.7 \times 10^{6}$ & $6.5 \times 10^{6}$ & $8.59 \times 10^{7}$ \\
Urbanicity & $46.89 \pm 68.80$ & 0 & 8.23 & 23.45 & 58.59 & 1752.07 \\
PM $_{2.5}\left(\mu \mathrm{g} \cdot \mathrm{m}^{-3}\right)$ & $0.12 \pm 2.94$ & -5.27 & -1.76 & -0.35 & 1.41 & 42.57 \\
$\mathrm{PM}_{10}\left(\mu \mathrm{g} \cdot \mathrm{m}^{-3}\right)$ & $10.05 \pm 1.05$ & 8.17 & 9.34 & 10.0 & 10.63 & 21.31 \\
& $16.24 \pm 1.87$ & 11.78 & 15.27 & 16.04 & 17.02 & 31.39 \\
\hline
\end{tabular}

$\mathrm{P} 25, \mathrm{P} 50$ and $\mathrm{P} 75$ represent the $25^{\text {th }}, 50^{\text {th }}$ and $75^{\text {th }}$ percentiles. 
Table 3. Characteristics of UK Biobank participants by residential green exposure ( $N=333$ 183).

\begin{tabular}{|c|c|c|c|c|}
\hline \multirow[b]{2}{*}{ Participant characteristics } & \multicolumn{4}{|c|}{ Residential greenness (NDVI) distribution } \\
\hline & Q1 & Q2 & Q3 & Q4 \\
\hline \multicolumn{5}{|l|}{ Mean (SD) } \\
\hline BMI $\left(\mathrm{Kg} / \mathrm{m}^{2}\right)$ & $27.62(4.8)$ & $27.46(4.7)$ & $27.38(4.8)$ & $27.40(4.7)$ \\
\hline Waist circumference (cm) & $90.86(13.6)$ & $90.37(13.5)$ & $90.35(13.4)$ & $89.82(13.1)$ \\
\hline Whole body fat mass $(\mathrm{Kg})$ & $25.05(9.6)$ & $24.95(9.5)$ & $24.91(9.7)$ & $24.80(9.4)$ \\
\hline Duration of walk (minutes) ${ }^{*}$ & $51.32(48.7)$ & $51.66(48.9)$ & $50.87(48.0)$ & $52.08(48.6)$ \\
\hline Age (years) & $56.31(8.1)$ & $56.79(8.0)$ & $56.39(8.2)$ & $56.67(8.1)$ \\
\hline SES (Townsend index) & $-1.48(2.8)$ & $-1.97(2.6)$ & $-0.99(3.1)$ & $-0.86(3.2)$ \\
\hline \multicolumn{5}{|l|}{$N(\%)$} \\
\hline Gender: Female & $45791(54.7)$ & 45439 (54.3) & $45185(54.5)$ & $45671(55.1)$ \\
\hline Male & $37918(45.3)$ & $38193(45.7)$ & $37696(45.5)$ & $37290(44.9)$ \\
\hline Ethnicity: British & 76845 (91.8) & 77409 (92.6) & $70389(84.9)$ & $73530(88.6)$ \\
\hline Others & $6864(8.2)$ & $6223(7.4)$ & $12492(15.1)$ & $9431(11.4)$ \\
\hline Education: None & $15576(18.6)$ & 14405 (17.2) & $13438(16.2)$ & $14191(17.1)$ \\
\hline College or University degree & $24483(29.2)$ & $24629(29.4)$ & $28537(34.4)$ & $27686(33.4)$ \\
\hline O levels/GCSEs/CSEs & $24677(29.5)$ & $24675(29.5)$ & $22034(26.6)$ & $22178(26.7)$ \\
\hline A levels/AS levels & $8909(10.6)$ & $9599(11.5)$ & $9260(11.2)$ & $8936(10.8)$ \\
\hline $\begin{array}{l}\text { NVQ/HND/HNC/Other } \\
\text { professional }\end{array}$ & $10064(12)$ & $10324(12.3)$ & $9612(11.6)$ & $9970(12)$ \\
\hline Employment status: Employed & 49096 (58.7) & $47746(57.1)$ & $48895(59)$ & $47066(56.7)$ \\
\hline Retired & $27822(33.2)$ & $29596(35.4)$ & $26877(32.4)$ & $28587(34.5)$ \\
\hline $\begin{array}{l}\text { Unemployed, home maker, } \\
\text { others }\end{array}$ & $6791(8.1)$ & $6290(7.5)$ & $7109(8.6)$ & $7308(8.8)$ \\
\hline Smoking status: Nonsmoker & $44995(53.8)$ & $46178(55.2)$ & $45260(54.6)$ & $45722(55.1)$ \\
\hline Previous smoker & $29323(35)$ & $29490(35.3)$ & $28822(34.8)$ & $29129(35.1)$ \\
\hline Current smoker & $9391(11.2)$ & $7964(9.5)$ & $8799(10.6)$ & $8110(9.8)$ \\
\hline \multicolumn{5}{|l|}{ Non-work transport mode**: } \\
\hline Walk/ cycle/ public transport & $16589(19.6)$ & $14532(17.2)$ & $20064(24.0)$ & $20356(24.2)$ \\
\hline Car/ motor vehicle & $67854(80.4)$ & 70069 (82.8) & $63587(76.0)$ & $63631(75.8)$ \\
\hline Obesity: None & $62147(74.2)$ & $63367(75.8)$ & $62718(75.7)$ & $62927(75.9)$ \\
\hline Yes & $21562(25.8)$ & $20265(24.2)$ & $20163(24.3)$ & $20034(24.1)$ \\
\hline Vascular problems: None & $58646(70.1)$ & $59010(70.6)$ & $58386(70.4)$ & 58307 (70.3) \\
\hline High blood pressure & $20237(24.2)$ & $19961(23.9)$ & $19924(24)$ & $19998(24.1)$ \\
\hline Heart attack/ angina/ stroke & $4826(5.8)$ & $4661(5.6)$ & $4571(5.5)$ & $4656(5.6)$ \\
\hline Diabetes: None & 79402 (94.9) & 79389 (94.9) & $78314(94.5)$ & $78844(95)$ \\
\hline Yes & $4307(5.1)$ & $4243(5.1)$ & $4567(5.5)$ & $4117(5)$ \\
\hline
\end{tabular}

${ }^{*} \mathrm{~N}=281061 ;{ }^{* *} \mathrm{~N}=336682$ 
Table 4. Association between residential green exposure and adiposity for $\mathrm{N}=333183$ participants of UK Biobank with valid individual-level and built environment data.

\begin{tabular}{|c|c|c|c|c|}
\hline $\begin{array}{l}\text { Residential green } \\
\text { (NDVI, } 500 \text { m catchment) }\end{array}$ & $\begin{array}{l}\text { Body mass index } \\
\qquad\left(\mathrm{kg} / \mathrm{m}^{2}\right) \\
\beta(95 \% \mathrm{Cl})\end{array}$ & $\begin{array}{l}\text { Waist circumference } \\
\qquad(\mathrm{cm}) \\
\beta(95 \% \mathrm{Cl})\end{array}$ & $\begin{array}{l}\text { Whole body fat } \\
\qquad(\mathrm{Kg}) \\
\beta(95 \% \mathrm{Cl})\end{array}$ & $\begin{array}{c}\text { Obesity } \\
\left(\mathrm{BMI}>\mathrm{kg} / \mathrm{m}^{2}\right) \\
\operatorname{RR}(95 \% \mathrm{Cl})\end{array}$ \\
\hline \multicolumn{5}{|l|}{ Model $1^{a}$} \\
\hline Mean greenness (per IQR) & $-0.077(-0.10,-0.06)^{*}$ & $-0.465(-0.52,-0.41)^{*}$ & $-0.060(-0.10,-0.02)^{\star *}$ & $0.981(0.97,0.99)^{*}$ \\
\hline \multicolumn{5}{|l|}{ Mean greenness categories } \\
\hline \multicolumn{5}{|l|}{ Low (Q1) - Ref } \\
\hline Q2 & $-0.135(-0.18,-0.09)^{*}$ & $-0.477(-0.59,-0.37)^{*}$ & $-0.041(-0.13,0.05)$ & $0.953(0.94,0.97)^{*}$ \\
\hline Q3 & $-0.183(-0.23,-0.14)^{*}$ & $-0.404(-0.51,-0.30)^{*}$ & $-0.004(-0.09,0.08)$ & $0.961(0.95,0.98)^{*}$ \\
\hline High (Q4) & $-0.159(-0.20,-0.12)^{*}$ & $-0.893(-1.00,-0.79)^{*}$ & $-0.172(-0.26,-0.09)^{*}$ & $0.955(0.94,0.97)^{*}$ \\
\hline \multicolumn{5}{|l|}{ Model $2^{\mathrm{b}}$} \\
\hline Mean greenness (per IQR) & $-0.099(-0.12,-0.08)^{*}$ & $-0.524(-0.58,-0.47)^{*}$ & $-0.096(-0.14,-0.05)^{*}$ & $0.974(0.96,0.98)^{*}$ \\
\hline \multicolumn{5}{|l|}{ Mean greenness categories } \\
\hline \multicolumn{5}{|l|}{ Low (Q1) - Ref } \\
\hline Q2 & $-0.097(-0.14,-0.05)^{*}$ & $-0.373(-0.48,-0.26)^{*}$ & $0.020(-0.07,0.11)$ & $0.966(0.95,0.98)^{*}$ \\
\hline Q3 & $-0.221(-0.27,-0.18)^{*}$ & $-0.506(-0.61,-0.40)^{*}$ & $-0.067(-0.15,0.02)$ & $0.949(0.93,0.96)^{*}$ \\
\hline High (Q4) & $-0.213(-0.26,-0.17)^{*}$ & $-1.033(-1.14,-0.93)^{*}$ & $-0.259(-0.35,-0.17)^{*}$ & $0.939(0.92,0.95)^{*}$ \\
\hline \multicolumn{5}{|l|}{ Model $3^{c}$} \\
\hline Mean greenness (per IQR) & $-0.123(-0.14,-0.10)^{*}$ & $-0.551(-0.61,-0.50)^{*}$ & $-0.138(-0.18,-0.10)^{*}$ & $0.968(0.96,0.98)^{*}$ \\
\hline
\end{tabular}

Mean greenness categories 
Low (Q1) - Ref

Q2

Q3

High (Q4)
$-0.109(-0.15,-0.07)^{*}$
$-0.385(-0.50,-0.27)^{*}$
$0.001(-0.08,0.09)$
$0.964(0.95,0.98)^{*}$
$-0.232(-0.28,-0.19)^{*} \quad-0.527(-0.64,-0.42)^{*}$
$-0.083(-0.17,0.00)$
$0.947(0.93,0.96)^{*}$
$-0.252(-0.30,-0.21)^{*} \quad-1.074(-1.19,-0.96)^{\star}$
$0.929(0.91,0.94)^{*}$

a models adjusted for individual-level covariates (age, gender, ethnicity, education, employment, smoking status, doctor-diagnosed cerebrovascular disease status and diabetes status).

${ }^{b}$ models adjusted for individual-level covariates and SES.

c Models adjusted for individual-level covariates, SES and built environment exposures (retail density, street walkability, terrain, and $\mathrm{PM}_{10}$ and $\mathrm{PM}_{2.5}$ ).

IQR: Interquartile range; Q1, Q2, Q3 and Q4: $1^{\text {st }}, 2^{\text {nd }}, 3^{\text {rd }}, 4^{\text {th }}$ quartiles of greenness respectively.

${ }^{*} p<0.001 ;{ }^{* *} p<0.01$. 
Table 5. Association between residential green exposure and travel behaviour

\begin{tabular}{lcc}
\hline $\begin{array}{l}\text { Residential green } \\
\text { (NDVI, } 500 \text { m catchment) }\end{array}$ & $\begin{array}{c}\text { Non-work travel mode; N=336 682 } \\
\text { (walk, cycle or public transport) }\end{array}$ & $\begin{array}{c}\text { Walking for PA; N=281 061 } \\
(>30 \text { min/day) }\end{array}$ \\
& OR $(95 \% \text { Cl })^{\mathrm{a}}$ & OR $(95 \% \mathrm{Cl})^{\mathrm{a}}$ \\
\hline & & \\
Mean greenness (per IQR) & $1.093(1.08,1.11)^{*}$ & $1.039(1.03,1.05)$ \\
Mean greenness categories & & \\
Low (Q1) - Ref & & $1.019(1.00,1.04)$ \\
Q2 & $1.023(1.00,1.05)$ & $1.026(1.00,1.05)^{\star *}$ \\
Q3 & $1.164(1.14,1.19)^{*}$ & $1.075(1.05,1.10)^{*}$ \\
High (Q4) & $1.211(1.18,1.24)^{*}$ & \\
\hline
\end{tabular}

a Models adjusted for age, gender, ethnicity, education, employment, SES, smoking status, obesity status, doctor-diagnosed cerebrovascular disease status and diabetes status; retail density, street walkability, terrain, $\mathrm{PM}_{10}$ and $\mathrm{PM}_{2.5}$. IQR: Interquartile range; Q1, Q2, Q3 and Q4: $1^{\text {st }}, 2^{\text {nd }}, 3^{\text {rd }}, 4^{\text {th }}$ quartiles of greenness respectively.

${ }^{*} p<0.001 ;{ }^{*} p<0.01$. 


\section{Supplementary Tables}

Supplementary Table 1. Demographic comparison of study analytic sample and UK Biobank full cohort.

\begin{tabular}{lcc} 
Participant characteristics & Study analytic sample & Full UK Biobank Sample \\
N & 333183 & 502649 \\
\multicolumn{2}{c}{ Mean (SD) or \% }
\end{tabular}

BMI $\left(\mathrm{Kg} / \mathrm{m}^{2}\right)$

Waist circumference $(\mathrm{cm})$

Whole body fat mass $(\mathrm{Kg})$

Duration of walk (minutes)

Age (years)

SES (Townsend index)

Gender: Female

Male

Ethnicity: British

Others

Education: None

A levels/AS levels

NVQ/HND/HNC/Other professional

Employment status: Employed

Retired

Unemployed, home maker, others

Smoking status: Nonsmoker

Previous smoker

Current smoker

Non-work transport mode: Walk/

cycle/ public transport

Car/ motor vehicle

Vascular problems: None

High blood pressure

Heart attack/ angina/ stroke

Diabetes: None

Yes
27.47 (4.8)

90.35 (13.4)

24.93 (9.6)

$51.4(48.5)$

$56.5(8.1)$

$-1.33(3.0)$

54.6

45.4

89.5

10.5

17.3

11.0

12.0

57.9

33.9

8.2

54.7

35

10.3

21.3

78.7

70.3

24.1

5.6

94.8

5.2
27.43 (4.8)

90.31 (13.5)

$24.86(9.6)$

$51.0(48.1)$

$56.53(8.1)$

$-1.29(3.1)$

54.4

45.6

88.6

11.4

17.3

11.2

11.9

57.8

33.6

8.6

54.8

34.6

10.6

21.8

78.2

70.2

24.0

5.8

94.7

5.3 
Supplementary Table 2. Association between residential green exposure, adiposity and odds of active non-work travel among participants of UK Biobank after adjusting for duration of walk (in minutes).

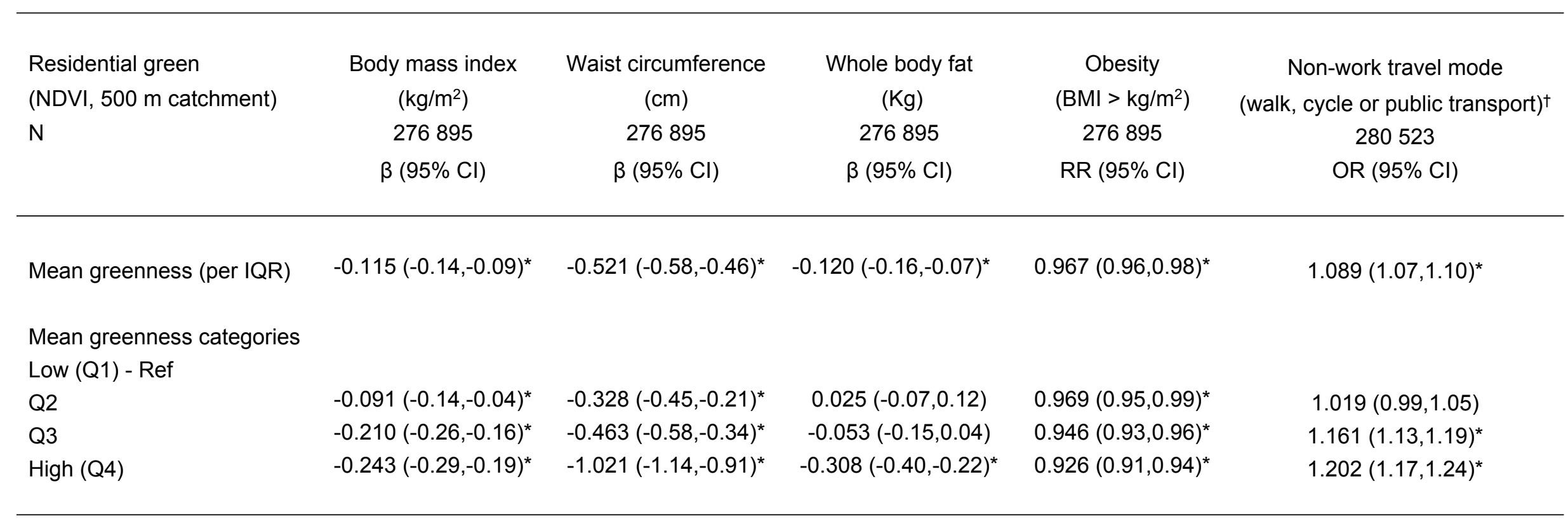

Models adjusted for age, gender, ethnicity, education, employment, SES, minutes walked, smoking status, doctor-diagnosed cerebrovascular disease status and diabetes status; retail density, street walkability, terrain, $\mathrm{PM}_{10}$ and $\mathrm{PM}_{2.5}$.

$\dagger$ Additionally adjusted for obesity.

IQR: Interquartile range; Q1, Q2, Q3 and Q4: $1^{\text {st }}, 2^{\text {nd }}, 3^{\text {rd }}, 4^{\text {th }}$ quartiles of greenness respectively.

${ }^{*} p<0.001 ;{ }^{* *} p<0.01$. 
Supplementary Table 3. Association between residential green exposure, adiposity and odds of active non-work travel among participants of UK Biobank after adjusting for work travel mode.

\begin{tabular}{|c|c|c|c|c|c|}
\hline $\begin{array}{l}\text { Residential green } \\
\text { (NDVI, } 500 \text { m catchment) }\end{array}$ & $\begin{array}{l}\text { Body mass index } \\
\qquad\left(\mathrm{kg} / \mathrm{m}^{2}\right)\end{array}$ & $\begin{array}{l}\text { Waist circumference } \\
\qquad(\mathrm{cm})\end{array}$ & $\begin{array}{l}\text { Whole body fat } \\
\qquad(\mathrm{Kg})\end{array}$ & $\begin{array}{c}\text { Obesity } \\
\left(\mathrm{BMI}>\mathrm{kg} / \mathrm{m}^{2}\right)\end{array}$ & $\begin{array}{c}\text { Non-work travel mode } \\
(\text { walk, cycle or public transport })^{\dagger}\end{array}$ \\
\hline \multirow[t]{2}{*}{$\mathrm{N}$} & 148133 & 148133 & 148133 & 148133 & 149597 \\
\hline & $\beta(95 \% \mathrm{Cl})$ & $\beta(95 \% \mathrm{Cl})$ & $\beta(95 \% \mathrm{Cl})$ & $\mathrm{RR}(95 \% \mathrm{Cl})$ & OR $(95 \% \mathrm{CI})$ \\
\hline Mean greenness (per IQR) & $-0.096(-0.13,-0.06)^{*}$ & $-0.480(-0.56,-0.40)^{*}$ & $-0.087(-0.15,-0.02)^{\star *}$ & $0.974(0.96,0.99)^{*}$ & $1.053(1.03,1.08)^{*}$ \\
\hline \multicolumn{6}{|l|}{ Mean greenness categories } \\
\hline \multicolumn{6}{|l|}{ Low (Q1) - Ref } \\
\hline Q2 & $-0.089(-0.15,-0.03)^{\star *}$ & $-0.354(-0.52,-0.19)^{*}$ & $0.011(-0.11,0.13)$ & $0.980(0.95,1.01)$ & $1.000(0.96,1.04)$ \\
\hline Q3 & $-0.189(-0.25,-0.12)^{*}$ & $-0.481(-0.64,-0.32)^{*}$ & $-0.011(-0.14,0.12)$ & $0.960(0.94,0.99)^{*}$ & $1.037(0.99,1.08)$ \\
\hline High (Q4) & $-0.199(-0.27,-0.13)^{*}$ & $-0.935(-1.10,-0.77)^{*}$ & $-0.248(-0.37,-0.12)^{*}$ & $0.941(0.92,0.97)^{*}$ & $1.122(1.07,1.17)^{*}$ \\
\hline
\end{tabular}

Models adjusted for age, gender, ethnicity, education, employment, SES, work travel mode, minutes walked, smoking status, doctor-diagnosed cerebrovascular disease status and diabetes status; retail density, street walkability, terrain, $\mathrm{PM}_{10}$ and $\mathrm{PM}_{2.5}$.

$\dagger$ Additionally adjusted for obesity.

IQR: Interquartile range; Q1, Q2, Q3 and Q4: 1 ${ }^{\text {st }}, 2^{\text {nd }}, 3^{\text {rd }}, 4^{\text {th }}$ quartiles of greenness respectively.

${ }^{*} p<0.001 ;{ }^{* *} p<0.01$. 